\title{
Most Recent Angina Pectoris Event
}

National Cancer Institute

\section{Source}

National Cancer Institute. Most Recent Angina Pectoris Event. NCI Thesaurus. Code C67095.

The most recent occurrence of angina pectoris. 